\title{
Theories of Poverty to the Integrative Theory. A Comparative Analysis: Accordance to the Situation of Iraq
}

\author{
${ }^{1}$ Aseel Sabah Abdullatif ${ }^{2}$ Prof. Madya Dr. Rusdi bin Omar, \\ ${ }^{3}$ Dr. Mashitah Binti Mohd Udin \\ College of Law Government and International Studies University Utara Malaysia \\ Ministry of Higher Education and Scientific Research, Republic of Iraq
}

\begin{abstract}
Many researchers on poverty suggest that the various ways in which poverty is perceived and measured are critical, as the various poverty measures tend to focus on one direction only, while the other factors of poverty are neglected. The main focus of this research is the review of empirical theories on poverty, poverty measures and outcomes. Later, we discuss the reasons for choosing an integrated theory to fight poverty in Iraq as needed by the Iraqi situation because of the complexity of the causes of poverty in Iraq
\end{abstract}

Keywords: Poverty, theory, Iraq, Comparative Analysis

\section{INTRODUCTION}

A lot of scholars and theorists have tried to develop various theories on poverty issues and poverty reduction policies. In general, their work has given significant contributions to the studies of the concept of poverty and poverty reduction policies. However, one should not only depend on a general theoretical framework. More importantly, in relations with the existing condition of poverty in Iraq, particularly after the US invasion, it would need a more relevant and suitable theoretical framework. This is because poverty in post-invasion Iraq is a complex phenomenon and needs to be analyzed critically within the context of the socio-political conditions of Iraq itself. In this regard, this study is intended to search for various theoretical frameworks, which are considered as more relevant to discuss poverty issues in general. Furthermore, it will discuss selected theoretical frameworks related to the policy of poverty reduction from a common perspective. Finally, it will discuss the use of a chosen theoretical perspective, which is considered as the most suitable and relevant to be applied in this study.

There are two categories in the theories of poverty:

The first focuses on the causes and roots of poverty, and how to measure poverty, identify the poverty gap and the poverty line. There are two theories here, the first is the vicious cycle of poverty theory and the second is the progressive social theory. The second one focuses on development, planning and policies to reduce poverty. The two theories here are the big push theory, and the basic needs theory. The description of the respective theories are as follows:

\section{THE VICIOUS CYCLE OF POVERTY THEORY}

According to this theory, the basis of poverty is the per capita income level. It is known that in developing countries the vicious cycle of poverty begins and ends with poverty. This vicious cycle starts from the low level of nutrition which leads to low level of health resulting in low productivity levels and ends with lower income levels (poverty) again. This theory is premised on the idea that individuals with high income can save and invest and can retain the same status, while individuals from the low-income group cannot afford to do so and is therefore unable to break the vicious cycle of poverty (Rohima, S., Suman, A., Manzilati, A., \& Ashar, 2013, P. 35)

However, the economic and social realities of developing countries suggest that there are multiple cycles. There is a vicious cycle for low level of education. It begins with a low level of education that leads to a low level of technical skills which results in a low level of income and thus ending with a low level of education. There is a vicious cycle on the lower level of real income and nutrition that results in a lower level of health and poverty vis-a-vis the level of investment and this is demonstrated in the results of the basic features of this theory. In addition, Nurkse believes that the under-developed States cannot break out of the cycle of poverty, unless the state implements huge investment programs directed to break the "vicious cycle of poverty". I would suggest that this theory on the impacts of poverty, the vicious cycle of poverty theory point to a weak link to fight against poverty in Iraq, because of, the challenges that must be faced in Iraq after the US occupation 
Theories of poverty to the integrative theory. A Comparative Analysis: accordance to the situation ..

in 2003. This is due to; the problem of poverty is a complex problem where it is affected by a lot of overlapping factors and the said factors vary from person to person as well as from one area to another. This is especially so for the situation in Iraq, which suffers from a considerable amount of corruption and the unstable security situation.

\section{PROGRESSIVE SOCIAL THEORY}

According to T.K. Bradshaw (2007) this theory focuses on several factors, and they are the political system, economic policy adopted in the country that do not support the principle of transparency in dealings between citizens, as well as the social structure. The social structure has an impact in the reality of poverty where income is reduced and there are no savings and the society is denied access to their well-being, by the reduction of opportunities to gain access to resources, for example, access to education, employment or support for small enterprises.

In the communities that suffer from the political, economic and social imbalances, there is a wide category of society that is living close to the poverty line and the reason for this is racial, sexual, and sectarian or there is a social stigma where tribal traditions prevail. All this leads to their chances becoming limited regardless of their competence and their personal capabilities. I would argue this theory. It also cannot be applied in Iraq. Because it does not address the problems that must be resolved. But only in the description of the case of poverty and the causes of poverty. While the paper aims to get to find solutions to the problem of poverty suffered by the Iraqi people.

\section{BIG PUSH THEORY}

The Big Push theory is that there is an urgent need in poor communities for a strong push or an intensive program with a specific minimum level of investment in order to overcome the obstacles of development and put the economy on track for growth. Rodin opined that large investments in the manufacturing sector will lead to a rapid increase in the accumulation of capital. Rodin considered that his theory (Big Push) is more feasible than the classic theories because this theory is more realistic and more (Jmona, 2010, P. 10; Sumaya, 2014, p. 8).

In fact, when this theory was applied in poor countries, it was proven that this theory cannot be applied successfully there because the Big Push theory requires a huge capital for the establishment of industrial projects, but poor countries do not have the money and also do not have a large enough market. In addition to that, this theory only focuses on the industrial sector and neglects all the other sectors.

Although this theory is ideal for countries that suffer from poverty, but it does not fit with this study because Iraq is a rich country and does not need financial support from outside. Iraq's predicament is that it suffers from internal problems such as corruption and an unstable security situation. I would suggest that due to the specificity of the situation in Iraq this theory cannot be applied there as we may not be able to obtain the desired results.

\section{BASIC NEEDS THEORY}

The theory of basic needs aims to increase the incomes of the poor by raising the level of development, which in turn will lead to an increase in national income. Several thinkers and economists are seeking, through this theory, to achieve the basic objectives for the citizens such as increasing the income of the poor, the elimination of unemployment, the provision of services, improvement in health care and education level as well as providing appropriate housing.

This theory is ideologically and politically supported because it aims to achieve social equity through the provision of services to the poor, such as education and health care, and providing job opportunities that leads to an increase in the gross domestic product (GDP) and also to achieve prosperity (Bukhari, n.d, P. 48). I would point out that this theory is ideal for social equality, but it only focuses on the consumer sector through its dependence on available resources to provide services to the poor without focusing on the production sector. An increase in production capacity will raise the standard of living in the long run.

I am of the opinion that these theories, the Big Push theory and Progressive Social theory, that have been adopted by Sumaya and Jmona, and Bukhari, are weak links, because the research problem is complex, especially in Iraq after the US invasion in 2003, which faces massive corruption (political and administrative) as well as huge waves of terrorism that threatens its security and stability. Since each of these theories can only be applied to a specific environment and specific conditions, it cannot be adopted in Iraq. These theories are not relevant to the situation in Iraq because each one of them needs specific conditions and also the fight against poverty in Iraq need to be tailor-made to fit the specific conditions. 
Theories of poverty to the integrative theory. A Comparative Analysis: accordance to the situation ..

\section{INTEGRATIVE THEORY}

From the above-stated discussions, it is clear that some theories which have been proposed previously are not appropriate to eradicate poverty in general and more specifically poverty issues in Iraq and its strategies for poverty reduction after the US intervention. In this regard, I propose the integrative theory to fight against poverty in Iraq as an alternative to the previous theories that have been discussed.

The author of the integrated theory Ken Wilber describes his theory as an attempt to place a wide diversity of theories and thinkers into one single framework. It is portrayed as a "theory of everything" trying "to draw together an already existing number of separate paradigms into an interrelated network of approaches that are mutually enriching." it is the arguably the first truly comprehensive or integrative philosophy.

Wilber explains the need for an Integral Approach in the following Way: In our current postmodern world, we possess an abundance of methodologies and practices belonging to a multitude of fields and knowledge traditions. What is utterly lacking, however, is a coherent organization, and coordination, of all these various practices, as well as their respective datasets. Through the Integral approach, we reveal the previously unseen possibilities for a better, more compassionate, and more sustainable future for all of us. In short, the integrative theoretical approach. It's coherent organization, suitable for all studies and methodologies. Wilber says it's the best way to make the world the right way ((Wilber, 2001, P. 55).

Al-Alami (2002, P. 65) in his book titled The Poverty points out that poverty is a complex phenomenon that arises due to multiple social, cultural, political and economic factors. So, researchers dealt with the issue of tackling poverty according to their own specialization. We find that the studies on poverty have identified different causes. The mismatch of results is due to the individuals themselves because the interpretation of the causes of poverty is according to the individual's perspective. Some of them look at it from the social perspective so they interpreted that poverty is a result of the lack of social justice. There are also researchers who look at it from the integrative perspective that combines multiple reasons.

In the same context, Al-Shamsi (2004, P. 7) in his article titled "Population policies and demographic transformation in the Arab world: the Gulf Cooperation Council" confirms that these factors collectively contribute to the spread of poverty. Therefore, development and poverty reduction concepts shift from the concept of economic growth based on manufacturing and fixed capital formation to the process of human development, political development, social development, and sustainable development.

\section{CONCLUSION}

This paper suggests that the integrative theory might be more appropriate to fight against poverty in Iraq. This theory can be distinguished from other theories due to the following reasons: First, the integrative theory makes concerted efforts to combine social responsibility with a comprehensive approach to face the challenges to reduce poverty. Top political leaders of the country can adopt this as a long-term effort to come out with strategic plans and policies for the implementation and realization of an integrated strategy.

Second, the reasons for the adoption by a researcher of the integrative theory is that it deals with all the aspects (social, cultural, economic and political) without neglecting any of the elements in an integrated application that includes in-depth study analysis and the identification of determinants on how to manage and evaluate the effects of internal and external case studies. Third, the main difference between the integration theory and other theories is that the integrative theory addresses all aspects, ideas, and elements without neglecting any part that covers the various theoretical approaches of the various specializations, particularly economics, sociology and politics. A lot of studies have described the integrative theory as the broader theory to study the phenomenon that has many challenges because it gives a full description and more than one option. It is a suitable to fight against poverty because this strategy is comprehensive and have long-term applications.

This paper will suggest the integrative theory as an analytical framework for understanding and be interpreting the challenges of poverty Iraq after the U.S. occupation. It attempts to explain the importance of the relationship between poverty and corruption, the lack of security and political sectarianism and will contribute valuable ideas to the evaluation of poverty in Iraq's. new political system after the US invasion. Figure 1.2 demonstrates from the perspective of the integrative theory the comprehensive theoretical framework for this study. 


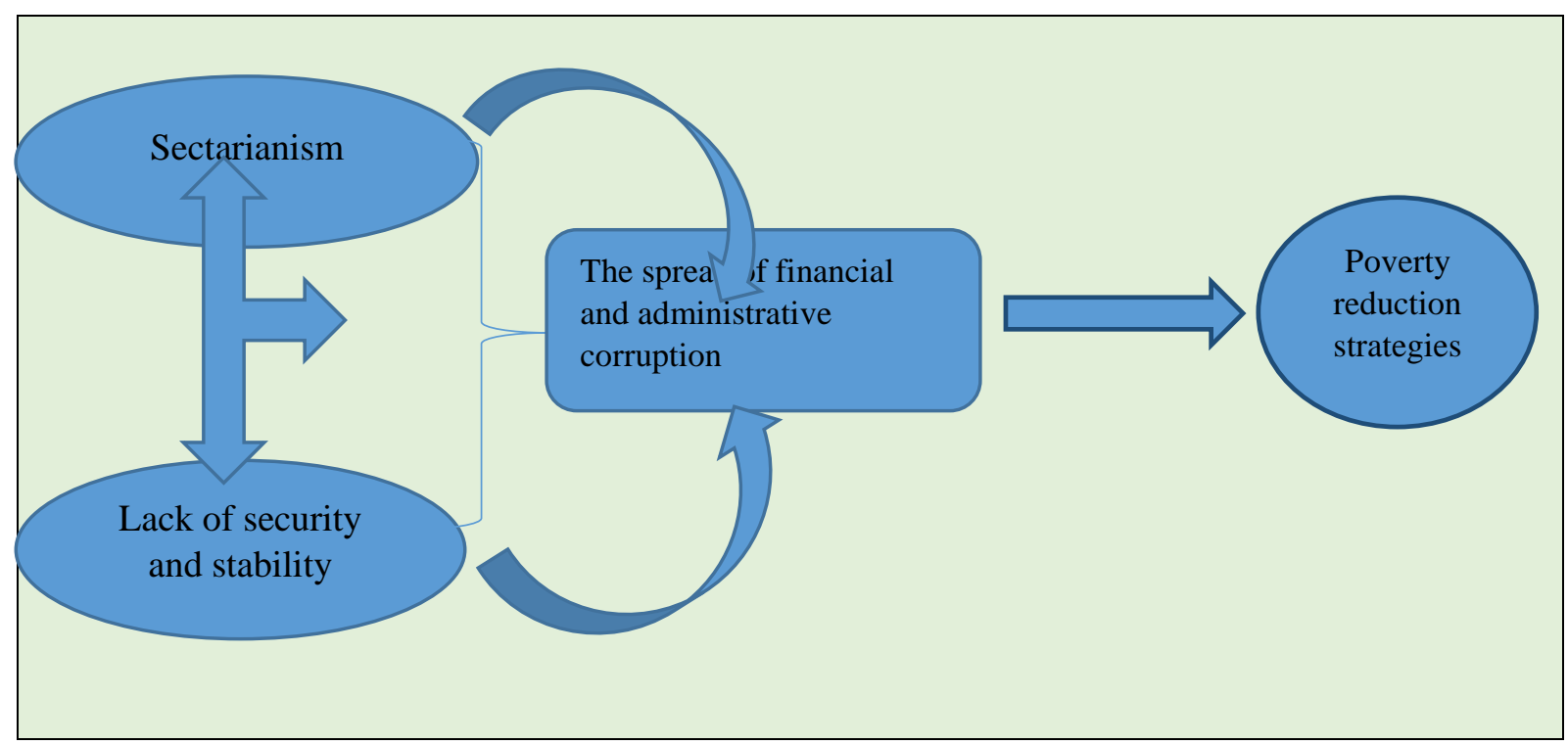

Source: Adopted from Al-Alami (2002, p. 65).

The Graphics above show the link between sectarianism and lack of security and stability, as it is linked to each other. As well as both of them lead to the spread of corruption, which is the main player, direct and frustrate the objectives of the poverty reduction strategies in Iraq.

\section{REFERENCES}

[1]. Rohima, S., Suman, A., Manzilati, A., \& Ashar, K. (2013). Vicious Circle Analysis of Poverty and Entrepreneurship, 35.

[2]. Bradshaw, T. K. (2007). Theories of poverty and anti-poverty programs in community development. Community Development, 38(7-25).

[3]. Jmona, S. M. a. H. (2010). About modern approaches to the study of the theory of economic development. National Forum on: Algerian Economy, 10. Retrieved from http://digitallibrary.univbatna.dz:8080/jspui/bitstream/123456789/63/1/ecoalg.pdf

[4]. Bukhari, A. A. H. (n.d.). Economic Development and Planning: economic growth and development theories, (23), 48.

[5]. Wilber, K. (2001). A theory of everything: An integral vision for business, politics, science and spirituality. Shambhala publications. Retrieved from https://books.google.com.my/books?hl=en\&lr=\&id=juxkSiDpHD0C\&oi=fnd\&pg=PP1\&dq=Ken+Wilber $\% 27 \mathrm{~s}+\% 22$ Integral+Theory\%22\&ots=5ZdILkkQmd\&sig=ppqKx2dzQCXXFoz6IpopiP6zvno\&redir_esc $=\mathrm{y} \# \mathrm{v}=$ onepage $\& \mathrm{q} \& \mathrm{f}=$ false

[6]. Al-Alami, A. (2002). The poverty. Rabat, Morocco: Al-Resala press.

[7]. Shamsi, M. S. (2004). Population policies and demographic transformation in the Arab world. The Gulf Cooperation Council. Eye: United Arab Emirates University. 